\title{
JOSÉ JOBSON ARRUDA, FAVORÁVEL
}

http://dx.doi.org/10.11606/issn.2237-1184.v0i33p389-393

\section{José Jobson de Andrade Arruda ${ }^{\mathrm{I}}$}

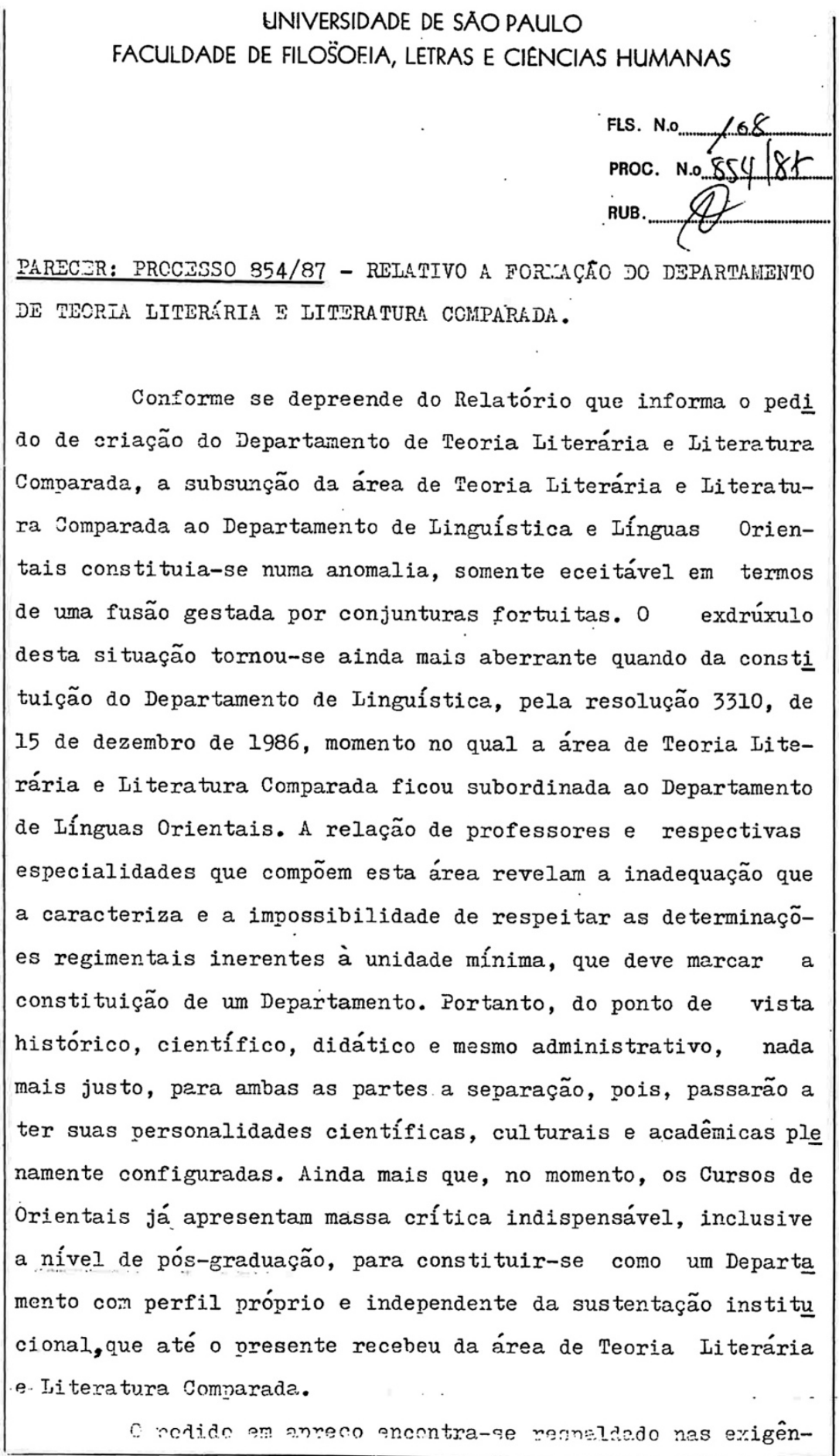

I Universidade de São Paulo, São Paulo, São Paulo, Brasil. 


\section{UNIVERSIDADE DE SÅO PAULO FACULDADE DE FILOSÖFIA, LETRAS E CIENCIAS HUMANAS}

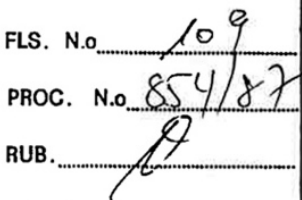

cias legais consubstanciadas no artigo 49 dos Istatutos, no artigo 23 do Regimento da FFLCH. A área apresenta atividade de ensino, embora em caráter optativo, mas que atende a uma grande demanda e a necessidades fundamentais do curso de Letras e, por isso, seria desejável fossem transformadas em dis ciplinas obrigatórias, o que, aliás, já se está proposto na reforma curricular em vias de implantação. $\Lambda$ pesquisa que se revela na quantidade e na qualidade da produção relacionada, nas teses dos pesquisadores ou na produção de seus orientandos a nível de mestrado e doutorado é das mais expressivas , contando com nomes dos mais celebrados na academia brasileira, entre os auais, destaca-se o do iniciador do curso de Teoria Geral da Literatura, em 1961, o emérito professor Antonio Can dido de Mello e Souza, secundado por nomes expressivos como os de Roberto Schwarz, João Alexandre Barbosa, Walnice Noguei ra Galvão, Davi Arrigucci, João Luiz Lafetá e outros. 0 expressivo número de 97 dissertações e/ou teses defendidas na área demonstra sua proficuidade; a publicação da maioria destes trabalhos, a sua qualidade. O relatório da CAPES integran te do processo em pauta insiste na excepcional qualificação do corno docente da área, integrado por 10 professores permanentes e 3 participantes não-permanentes.

Ficam atendidas também as alíneas b) e c) do artigo 49. O corpo docente permanente é composto por 2 professores titulares, 1 professor livre-docente, 6 professores doutores e 1 mestre, exatamente o mesmo número de professores que inte gravam 3. área de. Linguística guando foi pedida a sua criação. য়̃o cogitamos atender ao disnosto no texto de. Resolucão 171/73, 


\section{UNIVERSIDADE DE SÄO PAULO FACULDADE DE FILOSOEIA, LETRAS E CIENCIAS HUMANAS}

FLS. N.O PROC. N.o.854/87

RUB.

que exige um mínimo de 15 docentes, por analogia cón os pareceres constantes do processo no 225/87: da aỏvogada Ana íaria Cruz de ihoraes, do relator Prof. Ruy Aguiar da Silva Leme e dc asses sor jurídico Boris Fausto, para o qual, no referente à Resolução $171 / 73$, a matéria deve ser interpretada no sentido mais amplo e consoante o parecer, neste sentido, da advogada Ana Haria Cruz de ilioraes.

Nestes termos, encaminhamos favoravelmente o pedido. em tela, encarecendo sua aprovação pelo Douto CID.

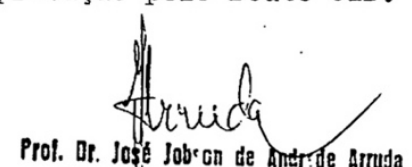

Che Jose Jobec on de ontride Arruta

Chalo do'Depurtomento do Historis

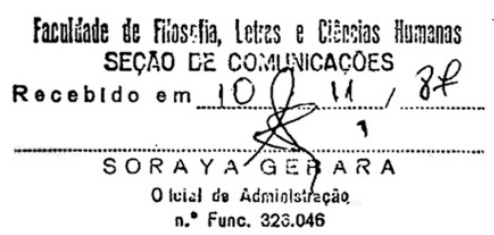

\section{APROVADO PELO CID}

Em Sessias ...79/Noo 187

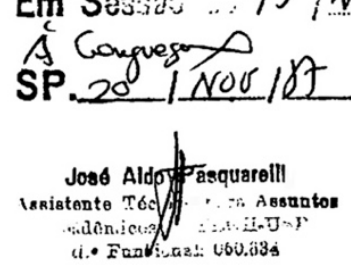




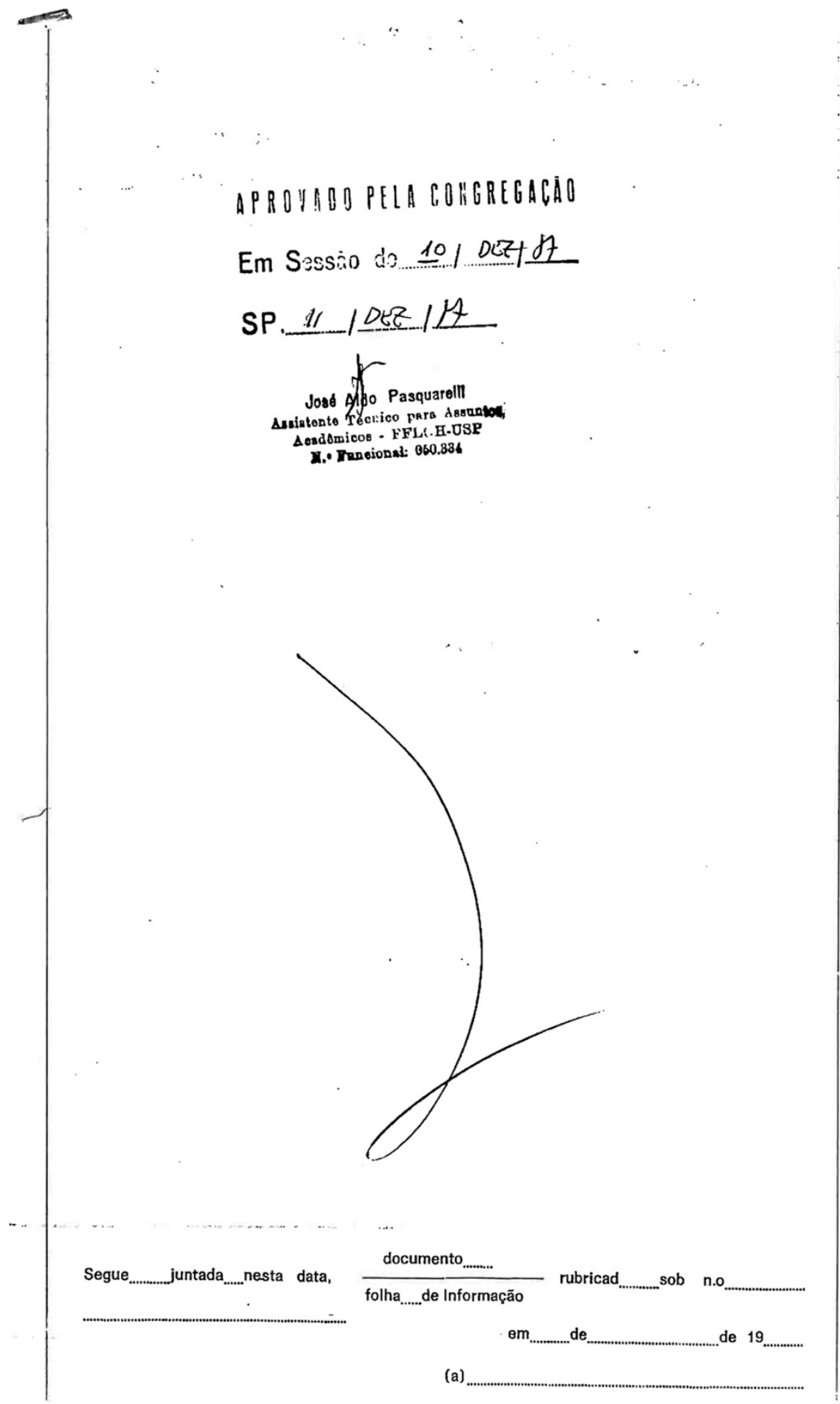


José Jobson de Andrade Arruda formou-se em História em 1966, doutorou-se em História Moderna em 1973 e tornou-se livre-docente em 1982 pela Universidade de São Paulo. Atuou no Conselho Nacional de Desenvolvimento Científico e Tecnológico entre 1986 e 88 e foi vicepresidente da Fundação de Amparo à Pesquisa no Estado de São Paulo em 1996. É professor sênior do Departamento de História e do Programa de Pós-graduação em História Econômica da USP, professor titular aposentado do Instituto de Economia da Universidade Estadual de Campinas e pró-reitor de Pesquisa e Pós-Graduação do Centro Universitário Sagrado Coração. Tem uma vasta lista de artigos, de capítulos e de livros publicados nas linhas de pesquisa de História Econômica e de Teoria e Metodologia da História Econômica. Entre os livros, Uma colônia entre dois impérios: a abertura dos portos brasileiros 1800-1808 (2008) e Historiografia: Teoria e Prática (2014). Contato: jjarruda@usp.br

ORCiD: https:// orcid.org/0000-0003-3061-6001 